\title{
A Study on the Conversion of VRML to X3D In A Highly Complex and Detailed Web3D World
}

\author{
Mursid W. Hananto ${ }^{1}$ and Ahmad Ashari ${ }^{2}$ \\ ${ }^{1}$ Department of Information Systems, Universitas Ahmad Dahlan, Yogyakarta, DIY, Indonesia
}

${ }^{2}$ Department of Computer Science and Electronics, Universitas Gadjah Mada, Yogyakarta, DIY, Indonesia

\begin{abstract}
X3D has been used by Web3D world developers around the world, some of them developed their world from the scratch, not as a converted version from VRML. Although VRML document can be converted to $\mathrm{X} 3 \mathrm{D}$ version, developers tend to choose to create a new world directly using X3D as it will produce clean documents. This choice can be tough to be taken when the objective is to create a highly complex Web3D world which is constructed almost entirely by polygons, and the bitmap images are used only as complements, used as the skin for 3D objects. Another choice was converting the existing VRML version of the site to its $\mathrm{X} 3 \mathrm{D}$ version. The only remaining problem is that whether the converted version will have the same or even better performance than the original one. This paper discussed the initial steps to cut the development time of a Web3D world by converting the VRML to X3D version. Results from the comparison have shown that mostly converted parts from the target world have similar looks and behaviour close to the original parts. A slight increase in performance numbers were noted, no significant differences were found, with only few inconsistencies. Therefore, a full conversion from VRML to $\mathrm{X} 3 \mathrm{D}$ is recommended for the site to be executed.
\end{abstract}

Keywords: Conversion, VRML, X3D, Complex, Detailed, Web3D.

\section{Introduction}

Complex and detailed 3D world with large visual area can often be seen on the internet, some of which are used to display the contents of a particular region, for example, a city [1]. Several methods of development have been used to create large-scale world by utilizing either VRML as well as X3D format, such as Virtual Kelp Forest [2] as the result of 2 groups working together to create the whole 3D model, Victoria Square in Gorizia [3] that used laser scanning and photogrammetric 3D, browsing the Ginza city by scanning its urban spaces [4], or 3D city models based on transportation and integration of urban 3D CityGML models [5]. Each of these worlds have particular feature in accordance with the purpose of their development, and they are also have common features that correspond to the document format used. Newer X3D format offers many features that are not contained in VRML. These new features promise the improvement of both visual quality as well as navigation performance and user experiences while visiting any Web3D site that uses this format, among other things. X3D also solved some issues in VRML [6], thus making it more attractive for Web3D developers.

Previous study for the use of X3D as the successor of VRML has been done in some researches, such as in [7] where VRML and X3D were discussed as the tools for scenario authoring and visualization in the form of $3 \mathrm{D}$ simulation, and in [8] where VRML were used to build a set of prototypes to make it easy for modelers to choose common dynamic model types in their multimodels, and then they switch to X3D since XML has many benefits for model design. Comparison studies on the conceptual parts of various Web3D format type has also be done in [9] by evaluating and comparing some technologies for 3D graphics for their web applications, and [10] which reviewed theadvantages and disadvantages of many $3 \mathrm{D}$ technologies for web including VRML and X3D, but both comparison did not specifically examine the actual elements of the scenery nor the world that forms each particular document format.

To utilize the new standard, a Web3D world built using VRML format may be rebuild using X3D format. Therefore, the resulting world should be able to utilize many additional features provided by X3D. On a world which has low complexity, the development process from scratch will not yield too many works to be done. If there are too many objects with complex and detailed polygons in an area that considered large in size based on their original real-world object dimension, then there will be a substantial quantity of works to be done. It was necessary to figure out whether a conversion was more feasible than to re-develop a highly complex Web3D world which has enormous area of visualization and thousands of complicated 3D polygons. 
This paper discusses about a comparison on the use of $\mathrm{X} 3 \mathrm{D}$ version on some elements of a world with highly complex and detailed objects converted from the original VRML version, using objects taken from 3rd Campus of Universitas Ahmad Dahlan (UAD) Web3D site [11]. This world has a very high display complexity not only because it is completely visualizing a whole complex of buildings in a very large area, it also extensively uses polygons for almost all parts of the world, including small details. The world does not use digital images to replace polygons, unlike other large-size Web3D worlds which do so when they have a very large number of complex and detailed objects to be visualized. Examples of Web3D worlds which heavily use raster images as the replacement for $3 \mathrm{D}$ shapes are the Web3D site of Old Prague [12], the Web3D site of North Campus [13] and Central Campus [14] of UCLA, and the Virtual Campus of NTU [15]. The use of raster images significantly reduce the resources needed to display the sceneries even though this method significantly decrease the visual details.

Raster images were used at minimum and only for specific areas which suitable, eg. as a skin for objects or as textures for a wide and uniform area such as floor and roof. By doing a comparison on the results of the conversion against their original ones, it is expected to be known the feasibility of full conversion on this complex and enormous Web3D world. Comparison is also expected to show the impact of using these two different standard format, so it can be determined whether the result will need more adjustments after conversion or not.

\section{Methods}

\subsection{Web3D Standards}

VRML has undergone some changes, from the initial format that emerged in 1995 as VRML 1.0 specification [16] and then became VRML 2.0 in 1996 [17]. After the specification became VRML97 [18], another amendment was done so that the format officially became VRML97 Amendment 1 [19] which is the latest VRML standard. An additional feature, External Authoring Interface (VRML97 EAI) was added in the specification in 2006 [20]. VRML format is widely used by developers, particularly since this format is supported by many 3D modeling softwares making it easier to develop complex worlds.

$\mathrm{X} 3 \mathrm{D}$ as the newer standard for Web3D Consortium has emerged since 2004 as ISO/IEC 19775-1 [21]. This format has more additional features compared to VRML, so that its ability in displaying 3D cyberspace become better. Among the features that are unique of $\mathrm{X} 3 \mathrm{D}$ is the addition of new nodes and capabilities, the introduction of additional data encoding formats, and the division of the language into functional areas called components [22]. Further comparison to VRML will point out that in general there are some specific additions e.g. X3D design features include validity checking of content, componentized browsers for faster downloads, flexible addition of new hardware extensions, a lightweight Core Profile, and better script integration compared to VRML [23]. Just like VRML, X3D specification continues to be revised and amended by Web3D Consortium every 12 to 18 months to keep current with advances in 3D grahics processing [24]. Therefore, X3D can achieve a more wide spread use in many areas.

As X3D expresses the geometry and behaviour capabilities of VRML using XML [25] which has become an unchallenged standard for the representation and exchange of data on the web [26], X3D documents must also follow the rules of writing used in XML. Nevertheless, X3D documents can be written using a writing style as used in classic VRML encoding [27], so developers who are more familiar with the VRML writing style can choose this way. Different encoding can also be seen by the document file extensions used. If the document is written in XML encoding then the document file extension is .x3d, whereas when written in VRML encoding, the extension is .x3dv. Just as in VRML, X3D document file size can also be reduced by compression using GZIP tool [28]. Unlike VRML where the specification is made as a single document, $\mathrm{X} 3 \mathrm{D}$ consists of several specification documents [29]. Although this may make X3D reference is not so simple as VRML, but this allows further expansion easier. Full specifications of $\mathrm{X} 3 \mathrm{D}$ can be seen in Fig. 1.

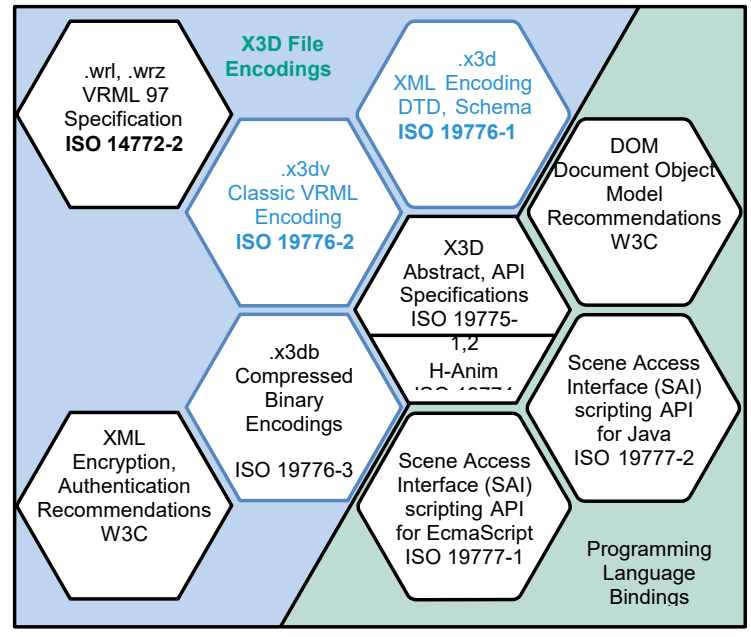

Fig. 1 Specifications in X3D [29]. 
Objects in a world that make up a particular scenery can be made in several ways. Among them is to define a basic object which has been provided by each format, or defines a complex object independently by determining a series of coordinates which will form the object. The second way can take advantage of commercial 3D modeling software so preparation of complex 3D object can be done quickly with high precision. Objects created with the such software can be exported into VRML or X3D document format.

\subsection{Comparison Method}

This research was in the form of comparative experiments on the use of X3D document formats compared with VRML format which has already been used by UAD 3rd Campus Web3D site. The experiments have initial objective which was to find out whether VRML or X3D format version is more suitable for the UAD 3rd Campus Web3D site. As the experiments went on the way, the objective was shifted to address more specific problem, that is, to find out whether the complete world conversion from VRML to X3D is feasible or not. To obtain that information, the comparison has been done on: (a) document size resulted, (b) how fast the browser displays its results in a variety of modes (time-based, not framebased), (c) how objects are displayed intact (similiarity with the original objects), and (5) browsing performance of the parts/components on each format.

Only some parts of the UAD 3rd Campus Web3D site that have been used as comparison materials. Therefore, no total conversion has been done. This is primarily because current Web3D world of UAD 3rd Campus has been developed as a distributed world, even though the components which form the complete world were not placed on separate servers. A direct total conversion has a number of probabilities to inflict problems in the form of external document linkages error. To avoid that, the world components for experimental use have been manually converted from VRML to X3D format, one at a time. Since the number of individual components were very large, conversion of complete world or all forming elements would take longer time than the planned research time. This is another reason for selecting only some of the components to serve as comparison materials.

Component object categories selected as the representatives for comparison are as following:

1. Complexity: Components which are considered simple (polygon side amount that was less than 10), medium (polygon side amount from 10 to 100), and complex (polygon side amount that was more than
100 ), as the representatives for complexity number comparison. Amount of sides counted also includes those inside the object, the ones invisible to visitors. 5 components were taken as samples for each complexity (15 in all).

2. Dimension: Components which are considered small in real-time dimension (less than $1 \mathrm{~m}^{3}$ in volume), medium ( 1 to $6 \mathrm{~m}^{3}$ in volume), and large (more than $6 \mathrm{~m}^{3}$ in volume), as the representatives for visual size comparison. Real-time dimension size data were taken from the original design provided by the actual developer of UAD 3rd Campus buildings. 5 components were taken for each object dimension (15 in all).

3. File size: Components which are considered small in uncompressed file size (less than 10KB), medium (10 $\mathrm{KB}$ to $100 \mathrm{~KB}$ ), and large (more than 100KB). 5 components were taken for each file size (15 in all).

4. Single descriptor: Components which developed by single document description without the need to be specified by other components. 10 components were taken as samples.

5. Multiple descriptor: Components which have to refer to other components, since they are single component which formed by more than one other components. 10 components were taken as samples, including their sub-components.

Comparisons were not done on raw documents which produced by $3 \mathrm{D}$ modeling software used to generate the source 3D models. Hence, the ones converted to X3D format were the optimized version of the original VRML documents - the actual online published version. The X3D documents themself were undergone minor adjustments so that they can connect with other linked documents when required. Visually added effects (including LOD, viewing range, lighting except their default, and navigation speed settings) were not enacted to compared world components. In contrast, the preset cameras which have been coded for various viewing angle were having some addition in number for some test scenes or objects as visualization alternatives, so that the review on performance and display can be done from various but similar sides.

\subsection{Format Conversion}

Instead of manually done line by line, conversion processes were done using format conversion services and softwares available on the Internet. In addition to saving time, manual conversion from VRML to X3D would more likely allow typographical errors, especially on the coordinate sequences used to form the complete objects. Primary conversion tool used in this research was InstantReality from Instantlabs [30]. 
Although the conversion were done by the conversion services, the task to make the conversion still has to be done by manually inserting the source code for each component (overall: 65 components) in the conversion system input box, and then wait for the conversion result. Original and converted documents were tested using already installed default browser which came with the operating system, with added plugin to view VRML and X3D documents.

The comparison processes also included all supporting raster images used as the skin for the components. No modifications were done on any of the raster images. All documents and raster files for each format were placed in the same local directories. All files for the documents compared in this research were the uncompressed ones, since the added time for the decompression processes for the compressed documents were not counted in this experiment. The compressed version were intended for real-time online comparison tests, in a beta-test which will be performed by selected visitors after all parts of documents in VRML format have been successfully converted to X3D format.

For the purpose of making the difference results can be seen clearer, the computers selected for comparison test sequences were 3 older type notebooks manufactured from 2002 to 2004. All computers were almost similar in specifications. 3D graphics especially rendered on browsers were known to extensively consume a large number of computer resources. A Web3D world displayed on computers with lower computing resources compared to current computer systems would hopefully provide a clearer results on the display and/or performance impact made by the effort to render any 3D objects on the installed browser.

\section{Comparison Results and Discussions}

\subsection{Grouping of comparison}

There were 5 group comparisons performed in this experiment: (a) average first render time, (b) average amount of memory needed, (c) average percentage of CPU use, (d) possibility of deformation, and (e) average autocruise navigation performance. Each comparison group will test all object on all categories.

For complexity, visual dimension, and file size categories, each object on all categories was tested 10 times, and the average number was picked as the representative result. Sometimes a test has to be repeated, so actually it took more than 10 times for some objects. The same test was done to each document type, so overall there were at least 300 tests have been done for each category, on each computer used as the testbed for comparison, for each comparison group. For single and multiple descriptor categories, the same 10 times tests for each object were also done. For both categories, there were at least 200 tests have been done, on each computer and for each comparison groups. Components selected from both format version also have been tested in the comparison process, to look for any errors that might occured during rendering.

Resumes of the results were shown below. Each comparison graphics are the average numbers of each document categories for every comparison test.

\subsection{Results for each group}

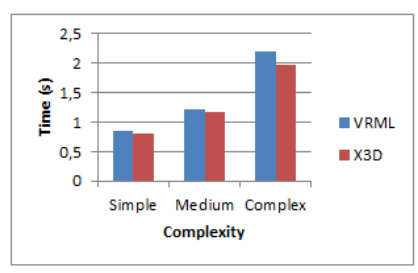

(a)

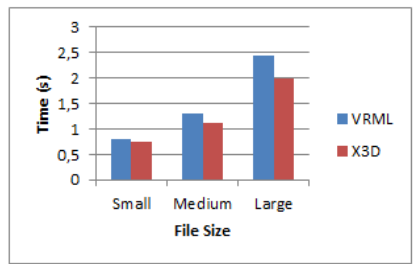

(c)

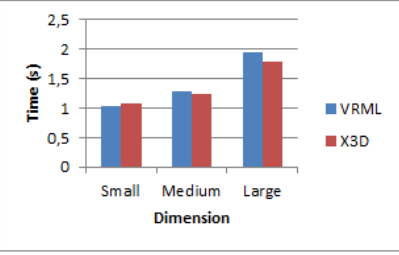

(b)

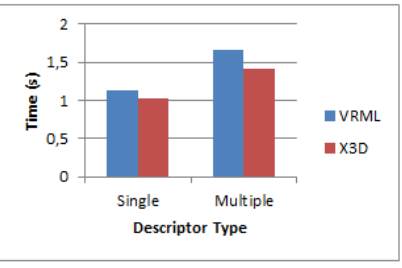

(d)
Fig. 2 Average first render time for each category: (a) complexity, (b) visual dimension, (c) file size, (d) component descriptor.

As seen on Fig.2a through Fig. 2d, comparison on the average first render time provided almost similar results in the overall numbers from each categories. When viewed from component complexity category, the newer X3D format version resulted in a slightly better performance numbers compared to its VRML counterpart. Even though a slight better performance numbers gained, the UAD 3rd Campus Web3D site components selected as representatives for the comparison did not provide a seemingly faster display when they were documented in $\mathrm{X} 3 \mathrm{D}$ format. The only exception was found on tests for file size subcategory. Even though only for a very small amount of time, some visible slight differences in display time impression were found on the last object comparisons (palem.wrl against palem.x3d). The more compact coordinate definition in X3D compared to its VRML version was believed as the cause for this result, as the last 
object has much longer coordinate definition than other objects used in this comparison.

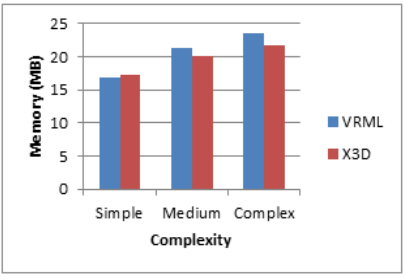

(a)

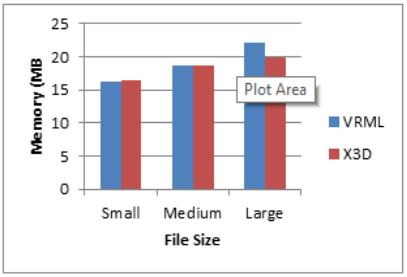

(c)

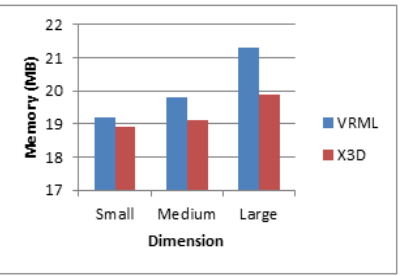

(b)

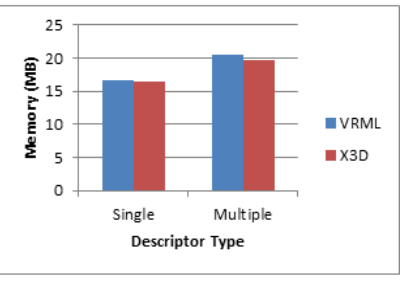

(d)
Fig. 3. Average amount of memory needed for each category: (a) complexity, (b) visual dimension, (c) file size, (d) component descriptor.

Comparison on the average amount of memory needed has provided results which were varied among objects. As seen on Fig. 3a through 3d, the variety can be clearly seen on component complexity and visual dimension categories. Although the numbers has shown a large range between the smallest and highest values, almost no significant differences were found in visual. There were 2 results which stood out among the others, both came from component complexity category. Both $\mathrm{X} 3 \mathrm{D}$ results differed for at least $0.5 \mathrm{MB}$ from their original VRML version. The results were acquired from each of the operating system's memory usage monitor which displayed the percentage of system memory used by the specific browser process. Monitor's update speed were set to normal, each process were monitored for 60 seconds, and the value used for comparison were the average of each second.

Comparison on the average percentage of CPU usage as seen on Fig. 4a through 4d has shown a more varied results than memory usage comparison. A small camera movement either walk, fly, pan, rotate, or any other 3D movement could trigger a burst in CPU usage, sometimes the difference from previous value can be more than $10 \%$ even though there were only a small shift in camera position. These percentage burst clearly occured on 2 computers used for testing, the only one which has a lower or almost no burst variable was the one with built-in 3D graphics accelerator adapter installed. CPU usage value capturing process was done by continuously capturing the screen of test bed computers in 1 second interval for 60 seconds of duration. The average of each second was used as the value for comparison. Overall by average values compared in this section, browser which displayed the $\mathrm{X} 3 \mathrm{D}$ format version has shown slight smaller percentage of CPU usage than the VRML version.

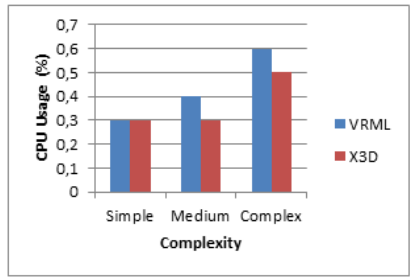

(a)

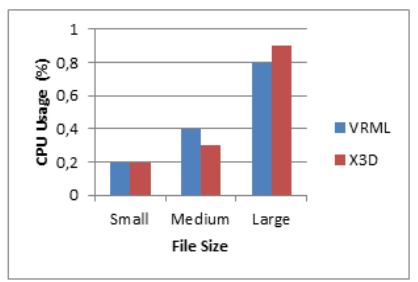

(c)

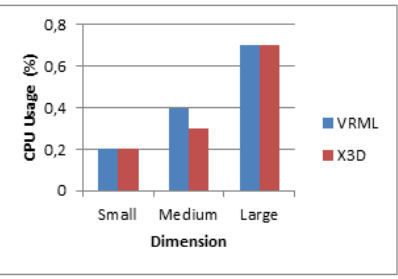

(b)

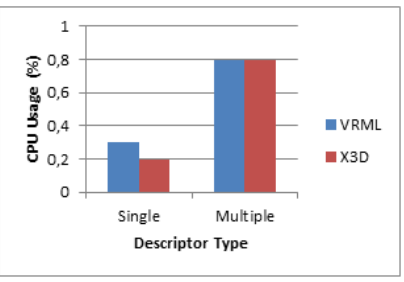

(d)
Fig. 4 Average percentage of CPU usage for each category: (a) complexity, (b) visual dimension, (c) file size, (d) component descriptor.

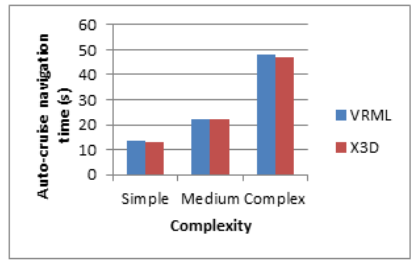

(a)

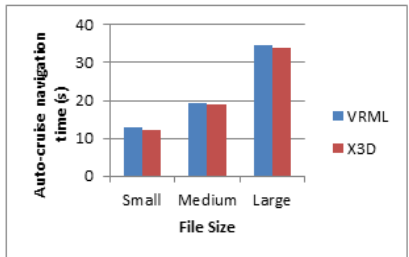

(c)

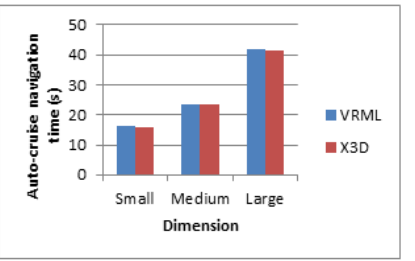

(b)

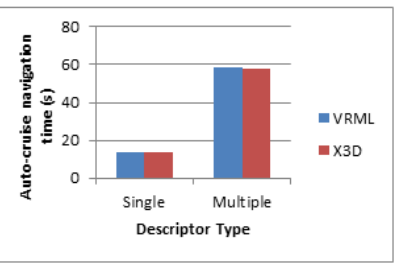

(d)
Fig. 5 Average auto-cruise navigation time for each category: (a) complexity, (b) visual dimension, (c) file size, (d) component descriptor.

As seen of Fig. 5a through 5d, comparison on the average auto-cruise navigation time has found almost similar result provided by both VRML and X3D version. Although a significant performance increase was expected from this comparison, it turned out that almost no differences found on all navigation speed used for the test, whether it was low, normal, or high. The difference values were very low, and although the same objects were rendered multiple times inside the same scene, the overall time needed for the process were still low, so it was deemed as insignificant in this experiments. Even so, in average the 
X3D document versions has shown the better result numbers compared to the VRML versions.

Comparison on the deformation has shown no significant deformation seen on almost all objects on both document format. Some slight inconsistencies were found on only one object in component descriptor category, as the converted version has a small off-side placement on one of its forming shape. After a thorough check on the source document format, there were no differences found on the coordinate and polygon description. In order to look for the source of problem, an additional browser with different plugin has been installed on the test bed computer, and the troubled scene was tested using the new set of browser and plugin. The additional test found out that the particular converted object has no deformation, just like the original version when displayed on the other set of browser and plugin used for the entire experiments. There were no other deformation report has been shown on all objects.

Other comparison done in this experiments was file size check. Based from the comparison results, file size produced in X3D compared to the VRML version were smaller, even though not all objects from the test scene were used for comparison. File size difference between VRML and X3D were bigger when source VRML file size were larger. It is important to be addressed here that file compression using GZIP has not been implemented to any of object files used in these experiments. Some objects which were used in the comparison can be drawn hundreds of times in the actual Web3D world or scene, if there were any decrease in file size then it can be expected that overall loading process for the same object in the browser will have a shorter time. Smaller file size can also means shorter transportation time for the scene elements, since the files have to be transported from the server to the client computers before being displayed on the visitors' Web3D browsers.

There were 2 comparisons that have not been done. The first one was the comparison on how predefined camera movement around the world will behave, whether on the first, second, or third floor. The second one was display effect, including viewing range, LOD, and all world preset conditions which placed on the primary world document. Both comparison have not been done in this experiment since they require a full conversion on all world objects. The experiments carried out for this research was to find out the feasibility of full world conversion for UAD 3rd Campus Web3D site. Since the objectives of the comparison were to get the conclusion whether the X3D version site will be created from scratch or converting from the existing world, the comparison which require a full world in newer format could not be done. Comparison for the compressed version were also not conducted, and all type of online test were not conducted either. Both tests will also need the complete converted and online version of the world.

\section{Conclusions}

From the results produced by the comparison processes, the conclusion is that the conversion to $\mathrm{X} 3 \mathrm{D}$ version from the former document format can produce a similar scenery with only a few almost unnoticeable differences in overall performance compared to its VRML version, in all types of sample objects or scene originated from the same world. The results also suggested that a complete conversion of the target Web3D world should be chosen instead of creating it from ground zero. Most elemental parts selected for comparison objects have shown close similarity on their looks and behaviour when tested on a variety of computers. Some slight better performance numbers also have shown up from the experiments, although only a few that were visible to notice and no significant difference found on the results compared to the original elements.

\section{Acknowledgments}

The authors would like to thank to the Department of Information Systems of Universitas Ahmad Dahlan (UAD) for providing the computer laboratory and its equipments for the experiments, and also for giving the opportunity to carry out the preliminary research in order to utilize the newer Web3D standard. The authors would also thank to the Department of Computer Science and Electronics of Universitas Gadjah Mada for providing the facilities to complete the research.

\section{References}

[1] N.F. Polys, A. Singh, and P. Sforza, "A Novel Level-ofDetail Technique for Virtual City Environments", in The 21st International Conference on Web3D Technology (Web3D '16), 2016, pp. 183-184, doi $>10.1145 / 2945292.2945322$.

[2] D. Brutzman, "Teaching 3D Modeling and Simulation: Virtual Kelp Forest Case Study", in The Seventh International Conference on 3D Web Technology (Web3D '02), 2002, pp. 93-101, doi>10.1145/504502.504518.

[3] D. Visintini, A. Spangher, and B. Fico, "The VRML model of Victoria Square in Gorizia (Italy) from laser scanning and photogrammetric 3D surveys", in The Twelfth International Conference on 3D Web Technology, 2007, pp. 165-168, doi $>10.1145 / 1229390.1229420$.

[4] A. Wakita and F. Matsumoto, "CT (city tomography)", in ACM SIGGRAPH 2002, 2002, pp. 308-308, doi $>10.1145 / 1242073.1242316$. 
[5] A. Koukofikis and V. Coors, "An Integration of Urban Spatial Data with Energy Simulation to Produce X3D City Models: The case of Landkreis Ludwigsburg", in The 20th International Conference on 3D Web Technology (Web3D '15), 2015, pp. 101-105, doi $>10.1145 / 2775292.2775325$

[6] A. E. Walsh, "Emerging Web3D Web Standards and Technologies", in Sixth International Conference on Humans and Computers, 2003, retrieved from http://mediagrid.org/publications/papers/Emerging_Web3D_ Web_Standards_and_Technologies.pdf.

[7] C. Blais, D. Brutzman, and S. Nicklaus, "Web-based 3D Technology for Scenario Authoring and Visualization: The Savage Project", in Interservice/Industry Training, Simulation, and Education Conference (I/ITSEC), 2001, retrieved from http://www.iitsecdocs.com/download/2001/HW8GULBEM M5X7A05

[8] T. Kim and P. A. Fishwick, "A 3D XML-based customized framework for dynamic models", in The Seventh International Conference on 3D Web Technology, 2002, pp. 103-109, doi $>10.1145 / 504502.504519$

[9] M. Waernẽr, "3D Graphics Technologies for Web Applications: An Evaluation from the Perspective of a Real World Application", Master thesis, Department of Electrical Engineering, Linköpings universitet, Linköping, Sweden, 2012, retrieved from http://liu.divaportal.org/smash/get/diva2:536657/FULLTEXT01.pdf.

[10]B. Turonova, "3D Web Technologies And Their Usability for The Project 3D Mobile Internet", Technical Report, Research and Development Center for Mobile Applications, Faculty of Electrical Engineering, Czech Technical University in Prague, Czech Republic, 2009, retrieved from http://www.rdc.cz/download/publications/Turonova_2009_3D Web.pdf.

[11]http://web3d.uad.ac.id/worlds/start.wrl.

[12]VOP Project Group, "Virtual Old Prague Project", http://dcgi.felk.cvut.cz/cgg/vsp2/.

[13]http://oldcda.design.ucla.edu/CAAD/ncampus/ncampus.wrz.

[14]http://oldcda.design.ucla.edu/CAAD/ccampus/ccampuz.wrz.

[15]http://www.ntu.edu.sg/home/assourin/vircampus/enter.wrl.

[16]G. Bell, A. Parisi, and M. Pesce, "The Virtual Reality Modeling Language Version 1.0 Specification", http://www.martinreddy.net/gfx/3d/VRML.spec.

[17]G. Bell, R. Carey, and C. Marrin, "The Virtual Reality Modeling Language Specification”, http://gun.teipir.gr/VRML-amgem/spec/index.html.

[18]The VRML Consortium Incorporated, "The Virtual Reality Modeling Language",

http://www.bitmanagement.com/developer/spec/vrml97speci fication.pdf.

[19]Web3D Consortium, "The Virtual Reality Modeling Language, Part 1-Functional specification and UTF-8 encoding, Amendment 1--Enhanced interoperability", http://www.web3d.org/documents/specifications/147721/V2.1/index.html.

[20]Web3D Consortium, "The Virtual Reality Modeling Language",

http://www.web3d.org/documents/specifications/14772/V2.0 /index.html.

[21]Web3D Consortium, Extensible 3D (X3D), Part 1: Architecture and base components, http://www.web3d.org/documents/specifications/197751/V3.2/Part01/Architecture.html.

[22]L. Chittaro and R.Ranon, "Web3D technologies in learning, education and training: Motivations, issues, opportunities", Computers \& Education, Volume 49 Issue 1, August, 2007, pp. 3-18, doi $>10.1016 /$ j.compedu.2005.06.002.

[23]D. Brutzman and L. Daly, X3D: Extensible 3D Graphics for Web Authors, San Fransisco, CA: Morgan Kauffman Publishers, 2007.

[24]D. Brutzman and L. Daly, "X3D: Extensible 3D Graphics Standard [Standards in a Nutshell]", IEEE Signal Processing Magazine, Volume 24 Number 6, November 2007, pp. 130135, doi>10.1109/MSP.2007.905889.

[25]V. Geroimenko and C. Chen, Visualizing Information Using SVG and X3D: XML-based Technologies for the XMLbased Web, London: Springer-Verlag London Limited, 2005.

[26]A. Aïtelhadj, "Efficient structural similarity computation between XML documents", IJCSI International Journal of Computer Science Issues, Vol. 10 Issue 2 No 1, March, 2013, pp. 421-436.

[27]ISO, "ISO/IEC 19776-2:2005, Information technology -Computer graphics, image processing and environmental data representation -- Extensible 3D (X3D) encodings -- Part 2: Classic VRML encoding", http://www.iso.org/iso/iso_catalogue/catalogue_tc/catalogue detail.htm?csnumber $=38018$.

[28]M. Limper, S. Wagner, C. Stein, Y. Jung, and A. Stork, "Fast Delivery of 3D Web Content: A Case Study", in The 18th International Conference on 3D Web Technology, 2013, pp. 11-17, doi $>10.1145 / 2466533.2466536$.

[29]Web3D Consortium, "Recommended Standards", http://www.web3d.org/standards/current.

[30]http://doc.instantreality.org/tools/x3d_encoding_converter/.

Mursid W. Hananto has Bachelor degree in Computer Science (1999) and Magister degree in Computer Science (2008) from Universitas Gadjah Mada, Indonesia. Currently a PhD student of the Department of Computer Science and Electronics at Universitas Gadjah Mada. Head of Computer Science lab of Computer Science Department (2002-2004) and Chair of the Department of Information Systems (2013-present), Faculty of Mathematics and Natural Science at Universitas Ahmad Dahlan, Indonesia. Research interests are Web Engineering and Applications, Multimedia Technology, and Information System Visualization. Member of the ACM.

Ahmad Ashari has bachelor degree in Electronics and Instrumentation Systems from Universitas Gadjah Mada, Indonesia (1988), Master degree in Computer Science from Universitas Indonesia (1992), and Ph.D degree in Informatics from Vienna University of Technology, Austria (2001). Head of Electronics and Instrumentation lab (2007-2011) and Head of Computer and Network Systems lab (2011-present), Faculty of Mathematics and Natural Sciences at Universitas Gadjah mada. Research interests are Data Communications and Computer Networking, Internetworking and Web, Distributed Systems, and Parallel Computing. Member of the IEEE. 